\title{
Applying the concept of "energy return on investment" to desert greening of the Sahara/Sahel using a global climate model
}

\author{
S. P. K. Bowring ${ }^{1}$, L. M. Miller ${ }^{2}$, L. Ganzeveld ${ }^{1}$, and A. Kleidon ${ }^{2}$ \\ ${ }^{1}$ Earth System Science Group, Wageningen University and Research Centre, Wageningen, the Netherlands \\ ${ }^{2}$ Max Planck Institute for Biogeochemistry, Jena, Germany
}

Correspondence to: S. P. K. Bowring (simon.bowring@wur.nl)

Received: 30 July 2013 - Published in Earth Syst. Dynam. Discuss.: 8 August 2013

Revised: 9 December 2013 - Accepted: 21 December 2013 - Published: 30 January 2014

\begin{abstract}
Altering the large-scale dynamics of the Earth system through continual and deliberate human intervention now seems possible. In doing so, one should question the energetic sustainability of such interventions. Here, from the basis that a region might be unnaturally vegetated by employing technological means, we apply the metric of "energy return on investment" (EROI) to benchmark the energetic sustainability of such a scenario. We do this by applying EROI to a series of global climate model simulations where the entire Sahara/Sahel region is irrigated with increased rates of desalinated water to produce biomass. The energy content of this biomass is greater than the energy input rate for a minimum irrigation rate of about $200 \mathrm{~mm} \mathrm{yr}^{-1}$ in the winter and $500 \mathrm{~mm} \mathrm{yr}^{-1}$ in the summer, thereby yielding an EROI ratio $>1: 1$, expressing energetic sustainability. Quantified annually, the EROI was $>1: 1$ for irrigation rates more than $500 \mathrm{~mm} \mathrm{yr}^{-1}$, progressively increasing to a maximum of $1.8: 1$ with $900 \mathrm{~mm} \mathrm{yr}^{-1}$, and then decreasing with further increases in the irrigation rate. Including the precipitation feedback arising from changes in moisture recycling within the study region approximately doubles these EROI ratios. This overall result varies spatially and temporally, so while the entire Sahara/Sahel region is irrigated equally, the western coastal region from June to August had the highest EROI. Other factors would complicate such a large-scale modification of the Earth system, but this sensitivity study concludes that with a required energy input, desert greening may be energetically sustainable. More specifically, we have shown how this type of EROI analysis could be applied as a metric to assess a diverse range of human alterations to, and interventions within, the Earth system.
\end{abstract}

\section{Introduction}

Numerous human activities revolve around the capture and use of energy. The potential now exists for humans to appropriate additional energy (e.g., renewable technologies), which on a large scale may alter the underlying dynamics of Earth system processes (e.g., via land-use change). Yet energy on Earth is limited by the flow of incoming solar radiation, its "heat of formation", gravitational attraction by celestial bodies, and by the current stock of fossil fuels. Thus, such interactions can only be sustained over the long term if the energy output appropriated is greater than the energy input required to do so. While the calculation of this relation, referred to as "energy return on investment" (EROI), is relatively common in other domains (e.g., industrial ecology), its use for assessing human interactions within the wider Earth system is relatively new (Hall et al., 1986).

The main objective of this paper is to show how EROI can be applied to the hypothetical scenario of large-scale desert greening of the Sahara/Sahel, in order to demonstrate the usefulness of the metric in the context of the Earth system. Exploring the use of EROI in this (example) scenario is relevant, as while research has shown that a green $\mathrm{Sa}$ hara might be possible (cf. Brovkin et al., 1998; Claussen et al., 1999), and that irrigated plants could be grown in such arid environments (e.g., Ornstein et al., 2009; Becker et al., 2013), the question remains as to whether greening the desert would be energetically sustainable - and hence "rational", from this perspective. The Sahara/Sahel region clearly receives considerable sunlight for plants to utilize, but the lack of soil moisture is the limiting factor on growth. Providing this moisture is likely to require continuous technological - 
and hence, continuous energy - input to sustain an energy output (i.e., biomass).

Additionally, this irrigation water will eventually be released into the region's atmosphere by way of evaporation and evapotranspiration. This additional water may precipitate within the desert greening region and lessen the need for irrigated water, or that additional water could be transported outside the region and thereby lost. Therefore, quantifying EROI for such a hypothetical scenario requires the modeling of interactions between the irrigated land and the atmosphere, and could be enhanced by simulating a variety of irrigation rates so that the biomass energy output, and the energy input required to grow that biomass, can be compared. While these results will potentially be biased by the vegetation and atmospheric models, our intention here is not to support or negate the practicality of desert greening, but rather clearly illustrate how EROI can capture the dynamics of a forced alteration to the Earth system.

\subsection{Energy return on investment}

The "return on investment" is commonly applied in economics, both for its historical and future relevance. A similar energetic quantification can also be applied to our actions and their results within the Earth system. This was first done by Hall et al. (1986) and is now known as energy return on investment, or EROI (Murphy and Hall, 2010). EROI quantifies the ratio between the actual and expected energetic outputs from a given action ( $\left.E_{\text {out }}\right)$ and the actual and expected energetic inputs to that process $\left(E_{\text {in }}\right)$, implying its sustainability in these terms if that value exceeds 1.0 (Murphy and Hall, 2010). It is defined in its simplest form as

$\mathrm{EROI}=\frac{E_{\mathrm{out}}}{E_{\mathrm{in}}}$

EROI is neither a complex nor particularly new concept, although actually applying it empirically to a scenario can be difficult (see Sect. 4). When applied to a given mechanism or process, EROI provides an aggregated thermodynamic metric that can compare widely varying techno-economic processes in their interaction with the environment (e.g., Bakshi et al., 2011). Variations in the definition of the $E_{\text {in }}$ and $E_{\text {out }}$ in Eq. (1) include energy (Murphy and Hall, 2010), exergy (Gutowski et al., 2009) and emergy (Odum, 1996). EROI or slight variations in it have been predominantly used as tools for life-cycle analysis in process engineering, industrial ecology, and ecological economics (e.g., Valero and Valero, 2011; Patzek, 2008; Gutowski et al., 2009; Baum et al., 2009). EROI quantification can also be used in Earth system studies, from looking at the energy return on extracting natural stocks (e.g., oil) and flows (e.g., wind), to the embedding of such processes in specific space-time (e.g., geographical) contexts. We briefly expand on these examples with the following illustrations.
Applied to the context of oil and gas, its EROI in 1930 was $>100: 1$, showing that a very large energy output resulted from a small energy input. The increasing extraction and use of oil and gas made continual discoveries and extractions more difficult, so by 1970 , the EROI had decreased to $30: 1$. By 2005, the EROI for oil and gas had decreased further to between $18: 1$ and $11: 1$, as noted in Murphy and Hall (2010).

As a differing example, early wind turbines were relatively small in both height and blade length, resulting in an EROI of less than 10:1. Engineering and technological advancements in wind turbine technology resulted in taller towers with longer blades, making the present-day EROI for wind turbines $\approx 20: 1$ (Kubiszewski et al., 2010). Note that while technological and economies-of-scale type considerations could further increase the EROI, it cannot infinitely increase. The generation rate of wind power in the Earth system is limited (Peixoto and Oort, 1992), limiting the electricity production rate of wind turbines (Miller et al., 2011), which thereby limits the EROI regardless of the extraction technology utilized. This highlights the connection of EROI with the natural environment and the ability of a human-applied change to alter the EROI, making it a dynamic rather than static reflection of these considerations.

Still, both of the previous EROI examples are calculated globally and do not incorporate the spatial or temporal differences that are specific to each study region. For both the "oil and gas" and the "wind turbine" examples, the EROI may not be spatially or temporally constant. That is, the "process" EROI (of the abstracted technological process) may not equal the "actual" EROI (the energetic input and output of that process in a specific space-time or contextual setting). We can clarify this last point with a final theoretical example.

Consider the EROI of a $100 \mathrm{~km}^{2}$ photovoltaic array. The (manufacturing) energy input $\left(E_{\mathrm{in}}\right)$ would be relatively independent of the geographic location where the array is deployed. By contrast, the energy output $\left(E_{\text {out }}\right)$, which should include the electricity production rate and land-atmosphere effects related to the alterations to the surface, could be quite geographically dependent. Deploying the photovoltaic array to Greenland would produce less electricity both seasonally and annually than the same array deployed in Mexico. Additionally, drastic differences in the land-atmosphere interactions would be expected. Quantifying how EROI varies both spatially and temporally between such large-scale human projects, while also including the differences in Earth system dynamics is of specific interest to us here.

Note that although commonly described as an efficiency indicator, we use the term "sustainability" for EROI, since this captures its ability to describe whether the energy input to a process can be sustained by its energy output, whereas an efficient process is not necessarily energetically sustainable in this context. 


\subsection{Desert greening}

An increasing scarcity of energy sources globally, as well as the indirect consequences of combusting conventional sources, have motivated the exploration of means by which to optimally make use of the available incident solar radiation on Earth. On this trajectory, the increased utilization of sunlight influencing the deserts has obvious practical appeal, since they combine low biological productivity with high energy input. One scheme put forward as a means to make use of this is the irrigation of deserts to induce local plant productivity.

The term "desert greening" as we will use it here, refers to irrigating an arid region to grow biomass for food or biofuel, sequester carbon, and/or alter the land-atmosphere interactions of the region. This has been investigated along a variety of theoretical and practical lines (e.g., Kleidon et al., 2000; Ornstein et al., 2009; Becker et al., 2013). Given the waterlimitation of deserts, a common-sense source for irrigation is the desalination of seawater and its subsequent pumping to plant root zones. Thus, there are energy inputs required by desalination and pumping. Desert greening's output, in the form of plant material, can be described by the total energy latent in photosynthetic carbohydrate biomass, which in the same way as petroleum, can be converted into another form of energy via some process (e.g., the total energy that can be released by its combustion). An additional energy output in this particular scenario is that of precipitation feedbacks (described below) induced by water and energy balance changes; its energy value is simply a multiple of the input energy value.

Despite these straightforward observations regarding its energy inputs and outputs, the practicalities of actually implementing desert greening is currently disconnected from an EROI focus, which would ask: does the energy we put into this process actually exceed the energy we get out of it? That is, is it energetically sustainable? To be clear, this does not ask if desert greening is sustainable by "natural" processes, but whether maintaining a green desert by technological intervention is energetically sustainable. As mentioned, desert greening could be seen as a means of providing food, fuel and carbon sequestration in regions where biological productivity is currently very low, and socioeconomic activity extremely sparse. In the context of climatic change, food scarcity and rising populations, these possibilities imply that the desert greening concept is of considerable research interest in its own right.

Section 2 will describe the model and the associated experimental setup. In Sect. 3, we will show the EROI and climatic differences that result from increased rates of irrigation on the Sahara/Sahel study region. Section 4 puts these results into the context of previous biogeochemical and meteorological studies, including the limitations we perceive in interpreting our results. This study will then end with a brief Conclusion (Sect. 5).

\section{Methods}

This paper explores the spatial and temporal variation of EROI to differential input rates of irrigation water. The energy values used in the calculation of EROI were taken from the literature. Energy required per unit volume of desalinated and pumped water $\left(E_{\mathrm{DS}}\right)$ was taken from Ornstein et al. (2009) because their estimation included the energy required for pumping and pressurizing in the desalination process and for distribution to the mean height of the Saharan region $(450 \mathrm{~m})$, assuming use of current state-of-the-art technology (but not higher-efficiency drip irrigation). Thus $E_{\mathrm{DS}}=14.54 \mathrm{MJ} \mathrm{m}^{-3}$. The latent output energy - the standing carbohydrate energy generated by photosynthesis - of net plant productivity $\left(E_{\mathrm{NPP}}\right)$ was taken from Gebel and Yüce (2008) and further studied in Becker et al. (2013), because this was taken to be representative of Jatropha, which is an arid region plant. Thus $E_{\mathrm{NPP}}=18.5 \mathrm{MJ} \mathrm{kg}^{-1}$. Note that this value does not include any conversion of biomass into any particular end-use, which would entail a specific conversion efficiency for that use. The ratio of net primary productivity (NPP) output difference in each simulation $\left(\triangle \mathrm{NPP}_{\text {sim }}\right)$ and the corresponding irrigation rate $\left(\mathrm{IR}_{\mathrm{sim}}\right)$ can be inserted into Eq. (1) to give EROI ${ }_{\mathrm{A}}$ :

$\mathrm{EROI}_{\mathrm{A}}=\frac{\left(\Delta \mathrm{NPP}_{\text {sim }} \cdot E_{\mathrm{NPP}}\right)}{\left(\mathrm{IR}_{\text {sim }} \cdot E_{\mathrm{DS}}\right)}$.

We define a second EROI value, here designated as EROI $_{B}$, which adds the precipitation difference over the irrigated region to the NPP-output energy. An increase in precipitation $\left(P_{\text {rec. }}\right)$ can be considered an energetic gain that increases at the same rate as the energetic cost of desalinating the seawater. If we consider the irrigated region as a closed system, and (as here) ignore capital and other energetic costs of the desalination process, this value is equivalent to the "exergy return on investment" discussed in Bakshi et al. (2011). The equation for $\mathrm{EROI}_{\mathrm{B}}$ is given as

$\mathrm{EROI}_{\mathrm{B}}=\frac{\left(\Delta \mathrm{NPP}_{\text {sim }} \cdot E_{\mathrm{NPP}}\right)+\left(\Delta P_{\text {rec. }} \cdot E_{\mathrm{DS}}\right)}{\left(\mathrm{IR}_{\text {sim }} \cdot E_{\mathrm{DS}}\right)}$.

Note therefore that the rate of return on the energy investment (as a percentage) is given by $\left(\mathrm{EROI}_{\mathrm{value}}-1\right) \times 100$.

Given the extreme nature of this experiment and the number of necessary simulations, we use the PlaSim (Planet Simulator) global climate model of intermediate complexity (Lunkeit et al., 2007). This model is based on a low resolution general circulation model, a mixed-layer ocean with prescribed ocean heat transport, interactive sea-ice model, a simple land surface and vegetation model, and prescribed ice sheets. Simulations were completed using the T42 spectral resolution $\left(2.8^{\circ}\right.$ longitude by $2.8^{\circ}$ latitude $)$ and ten atmospheric levels. The terrestrial vegetation model used here was the Simulator for Biospheric Aspects (SimBA), which dynamically responds to the combination of land surface 
properties and climatic conditions (detailed description in Kleidon, 2006). These influences thereby inhibit/enable plant growth, which alter land surface properties, and in turn affect the energy and mass exchanges within the PlaSim climate model. Gross primary productivity (GPP) is also constrained by these influences, with net primary productivity (NPP) assumed to be half of the GPP value.

To simulate irrigation, a constant influx of water to the soil moisture box was introduced. This increase in irrigation is limited to the region of the Sahara and Sahel, hereafter referred to as the irrigated region. The extent of the irrigated region is based on a global biome map taken from Zeng et al. (2008), as their focus was on modeling vegetation in arid regions. This external specification is not related to PlaSim output because the aim here was to include the entire Sahara/Sahel rather than deliberate on definitions of aridity as applied to the region.

Twenty model runs were completed for 50 simulation years, with the last $30 \mathrm{yr}$ used for analysis to exclude model spin-up. The irrigation rate intervals were determined from expected feasible and necessary water inputs found in previous studies (primarily Ornstein et al., 2009; Becker et al., 2013, and from the output in our trial runs). These were set at $100 \mathrm{~mm} \mathrm{yr}^{-1}$ intervals from 0 to $1500 \mathrm{~mm} \mathrm{yr}^{-1}$, and at $500 \mathrm{~mm}$ intervals from 1500 to $3500 \mathrm{~mm} \mathrm{yr}^{-1}$, with the irrigation rate of $0 \mathrm{~mm} \mathrm{yr}^{-1}$ used as the control simulation. The latter was done to reduce total runtime. All other model parameters were set at their default values.

\section{Results}

The authors stress that the aim of this experiment is to demonstrate the applicability of EROI in assessing the impact of desert greening on diverse Earth system processes energetically. These calculations do not include energetic costs of specific production processes involved, such as fertilizer use and the overhead and maintenance energy costs for specific energy-input infrastructure used in desalination. EROI estimation of these quantities relates to a second-order question - namely, the EROI of a specific scenario - and imply a level of decision making by the researcher that is intrinsically "political", with huge variations in potential output. Future research should certainly address these in more detail, yet our focus here is on the application of EROI rather than the practicalities of large-scale desert greening.

\subsection{Regional sensitivities of EROI, temperature and energy balance}

Figure 1a shows the sensitivity of $\mathrm{EROI}_{\mathrm{A}}$ and $\mathrm{EROI}_{\mathrm{B}}$ during Northern Hemisphere winter (December-February; DJF) and summer (July-August; JJA) to the input irrigation rate. $\mathrm{EROI}_{\mathrm{A}}$ (based on biomass energy) and EROI ${ }_{\mathrm{B}}$ (which includes the biomass energy and the precipitation feedback)
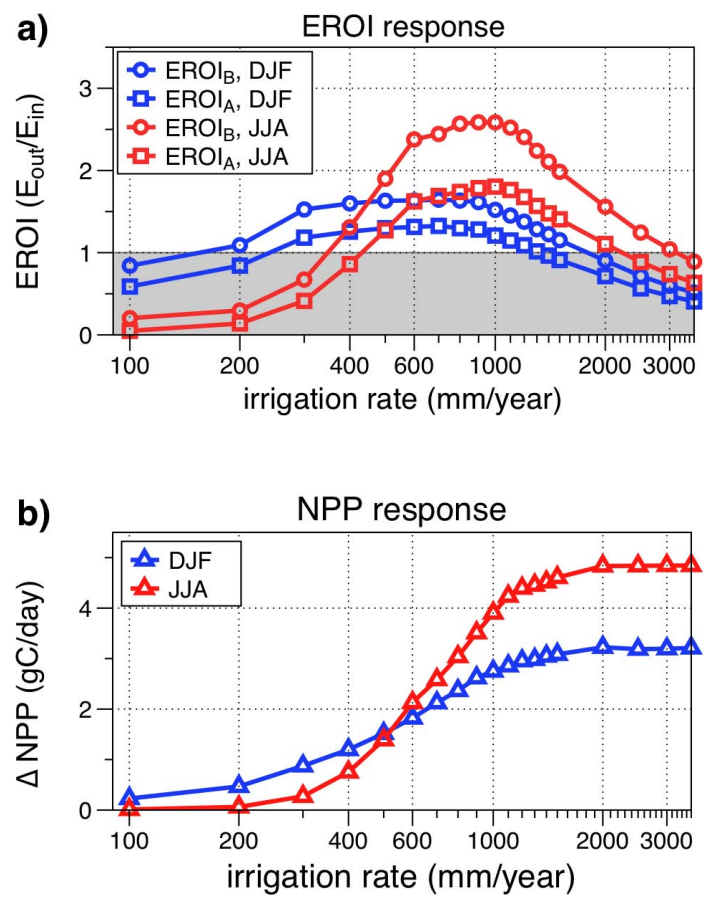

Fig. 1. (a) $\mathrm{EROI}_{\mathrm{A}}$ and $\mathrm{EROI}_{\mathrm{B}}$, and b) NPP, both shown as a function of the irrigation rate and averaged over the entire irrigation region. The seasonal mean for December-February (DJF) is shown in blue, and the seasonal mean for June-August (JJA) is shown in red.

are both almost half as large during the Northern Hemisphere winter than during the summer. Winter EROI is maximized at $700 \mathrm{~mm} \mathrm{yr}^{-1}$ of irrigation, while summer EROI is maximized at $1000 \mathrm{~mm} \mathrm{yr}^{-1}$. This applies to both $\mathrm{EROI}_{\mathrm{A}}$ and $\mathrm{EROI}_{\mathrm{B}}$. The annual mean optimal irrigation input for the maximum $\mathrm{EROI}_{\mathrm{A}, \mathrm{B}}$ is $900 \mathrm{~mm} \mathrm{yr}^{-1}$. At irrigation rates $\left(\mathrm{IR}_{\text {sim }}\right)$ lower than $400 \mathrm{~mm} \mathrm{yr}^{-1}$, EROI is lower in the summer than that in winter. The cause for this is straightforward. As shown in Fig. 1a, for $\mathrm{IR}_{\text {sim }}>400 \mathrm{~mm} \mathrm{yr}^{-1}$ the precipitation enhancement is greater in the summer (JJA) than during the winter (DJF), and in Fig. $1 \mathrm{~b}$, at $\mathrm{IR}_{\mathrm{sim}}>500 \mathrm{~mm} \mathrm{yr}^{-1}$ the summer NPP difference is also greater in the summer than that during winter.

What emerges in Fig. 1a is that optimal winter and summer irrigation input are different. The amount of water and consequently energy input actually needed vary seasonally, with implications for optimal water use efficiency. In the Northern Hemisphere winter, the maximum $\mathrm{EROI}_{\mathrm{A}}$ is $1.3: 1$ and the maximum $\mathrm{EROI}_{\mathrm{B}}$ is $1.6: 1$. In the summer, the maximum $\mathrm{EROI}_{\mathrm{A}}$ is $1.8: 1$ and the maximum $\mathrm{EROI}_{\mathrm{B}}$ is $2.6: 1$ Quantified annually (not shown), EROI declines at irrigation rates above $900 \mathrm{~mm} \mathrm{yr}^{-1}$.

Figure 2 shows the area-averaged seasonal precipitation difference, the latent and sensible heat fluxes, and surface temperature difference respectively. Declines in surface sensible heat are mirrored by increases in latent heat flux with increasing irrigation, which in turn depresses the surface 

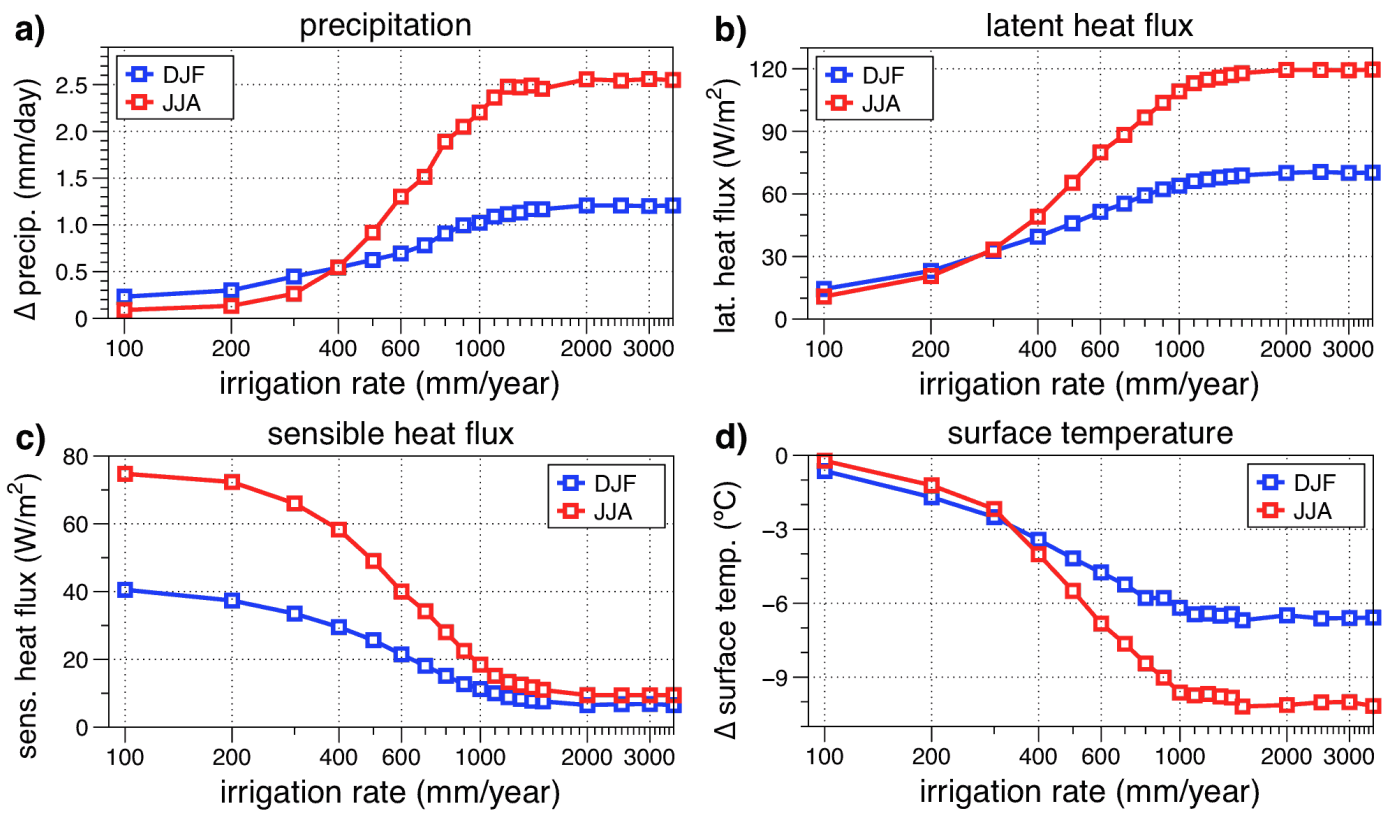

Fig. 2. Seasonal responses of the irrigation rate to common climatological variables: (a) precipitation, (b) latent heat flux, (c) sensible heat flux, and (d) surface temperature in response to the increased irrigation rate, averaged over the entire irrigated region.

temperature of the irrigated area. Changes in latent and sensible heat fluxes and surface temperature all saturate at between 1500 and $2000 \mathrm{~mm} \mathrm{yr}^{-1}$, which implies that evaporation is occurring at potential evapotranspiration, as well as a maximum in the cooling effect of water on the land surface at these irrigation rates. From Fig. 2d, we observe that surface temperature declines most during summer, reaching a maximum difference of about $-10^{\circ} \mathrm{C}$ at an irrigation rate greater than $1400 \mathrm{~mm} \mathrm{yr}^{-1}$, whereas during winter this figure is about $-7^{\circ} \mathrm{C}$. This is expected, given the increased solar energy input during the Northern Hemisphere summer.

\subsection{Spatiotemporal variations in EROI}

Figure 3 illustrates the seasonal spatial distribution of $\mathrm{EROI}_{\mathrm{A}}$ and $\mathrm{EROI}_{\mathrm{B}}$ for these two scenarios. These show that $\mathrm{EROI}_{\mathrm{A}}$ and $\mathrm{EROI}_{\mathrm{B}}$ are consistently high in a central-latitudinal band of the African continent (i.e., the Sahel) during both winter $\left(\approx 2-2.5\right.$ for $\mathrm{EROI}_{\mathrm{A}}, \mathrm{EROI}_{\mathrm{B}}$ respectively) and summer $\left(\approx 3-3.5\right.$ for $\mathrm{EROI}_{\mathrm{A}}, \mathrm{EROI}_{\mathrm{B}}$, respectively), whereas northern Africa exhibits the expected high seasonal EROI-variation, with some of the highest and lowest values across the irrigated region for the summer and winter respectively. The continental boundaries of the equatorward irrigated region also exhibit high EROI as will be discussed below. Note that this area is presently a grassland/forest transition region (shown in Fig. 1 of Zeng et al., 2008).

The greatest winter increases in NPP (Fig. 4g) are located on the western and central portions of the irrigated region. This region is climatologically driven by increased convergence of northeasterly trade winds and increased monsoonal winds - driven by significantly lower temperatures at the irrigated region's midlatitudes along the coast at this latitude. The wintertime combination of low insolation (and so NPP) and the relatively low change in continental precipitation, particularly over the irrigated region (Fig. 4e), explains why EROI peaks at a lower irrigation rate during winter. Outside of the irrigated region, wintertime trades advect irrigation water southwest into the Gulf of Guinea and the subequatorial African landmass (Fig. 4g). The greatest summer increases in NPP (Fig. 4h) are along the continental maritime boundary areas, particularly those in the west and north, which border the Mediterranean and the Atlantic Ocean.

\subsection{Climatic differences}

Such a large scale-modification of the terrestrial surface goes further than the addition of vegetation and localized effects of albedo and surface energy fluxes on climate variables. The extent of desert greening simulated entails highly visible global consequences resulting from the massive increase in moisture input, evaporation (Fig. 4a, b) and precipitation (Fig. 4e, f), which culminate in shifts of magnitude, space and time in both regional and global climatology. Note the southward shift in the global Hadley cell (Fig. 4e, f), in agreement with previous studies by Brovkin et al. (1998), Claussen et al. (1999) and Ornstein et al. (2009). A detailed discussion of the mechanics underlying this modeled shift can be found in the paper by Ornstein et al. (2009).

Accompanying this is a marked decrease in NPP and precipitation in southern Asia, as the inter-tropical convergence zone (ITCZ) shift alters the positioning of the Indian 

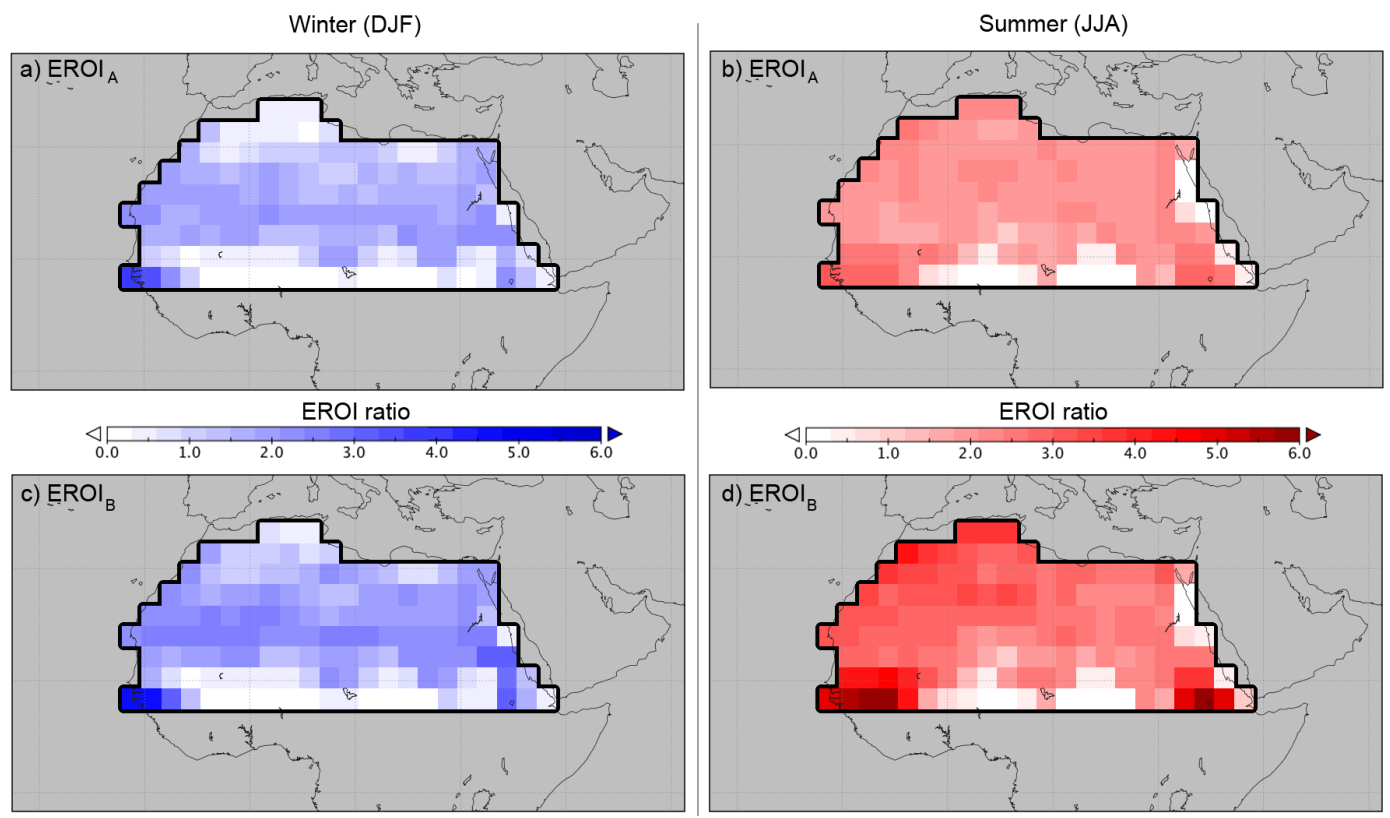

Fig. 3. Seasonal mean $\mathrm{EROI}_{\mathrm{A}}(\mathbf{a}, \mathbf{b})$ and $\mathrm{EROI}_{\mathrm{B}}(\mathbf{c}, \mathbf{d})$ over the irrigated region in DJF $(\mathbf{a}, \mathbf{c})$ and JJA $(\mathbf{b}, \mathbf{d})$. Winter values are taken from the $700 \mathrm{~mm} \mathrm{yr}^{-1}$ simulations, while summer values are taken from the $1000 \mathrm{~mm} \mathrm{yr}^{-1}$ simulations. The black solid line shows the outer bounds of the irrigated region.

Monsoon during the Northern Hemisphere winter. The impact of increased soil moisture in northern Africa on precipitation in the northern portion of South America was studied by Hagos et al. (2005), and is essentially reproduced here (Fig. 4f), evidenced by an increase in both NPP and precipitation in the region. There is also a strong increase in summertime NPP and precipitation in the Mediterranean portion of southern Europe. The latter two impacts are potentially important given the expected increase in frequency and intensity of these regions' respective drought periods under various climate change scenarios (Fussel, 2009).

\section{Discussion}

This section describes the physical mechanisms underlying our results, based on their agreement with previous studies. Although this is not the central purpose of this paper, the accordance of our findings with other research thereby supports the EROI results. The discussion will first focus on how we can interpret the results to view the highest EROI regions from our simulations, and then comment on the physical causes of these locations. The larger scale impacts of desert greening on energy, circulation and precipitation regimes are then treated, followed by a short summary and discussion of the limitations inherent in, and future research implied by, our study.

\subsection{Interpretation of the results}

While these results hold for the large-scale scenario used here, we stress that isolated irrigation of the high-EROI areas identified by our experiment is unlikely to produce the same absolute or relative (to other grid cells') EROI values. This is because the precipitation feedbacks involving irrigation and subsequent surface-atmosphere interactions depend strongly on the scale at which these processes are resolved by the applied model system. In other words, the spatial variance in EROI in our results are specific to the large-scale nature of our experiment. Further investigation would be required to identify high-EROI grid cells that are relatively independent of irrigation scale; this would require a far greater array of experimental runs to determine than the number employed here. Instead, we reiterate that this is a conceptual study, with the intention of illustrating how the EROI-metric and its underlying dependencies, such as excluding or including the precipitation feedback, can be applied to such a large-scale scenario of forced human intervention. This sharpens the focus to the large-scale EROI and climatic differences specific to this study's experimental setup, while being clear about its more practical limitations.

\subsection{Regions of highest EROI}

Regions with the highest EROI occur at the western coastal boundary of Africa. From the maps, we can infer that this occurs due to much higher NPP and precipitation in these areas, which are in turn the result of higher seasonal solar 
a)

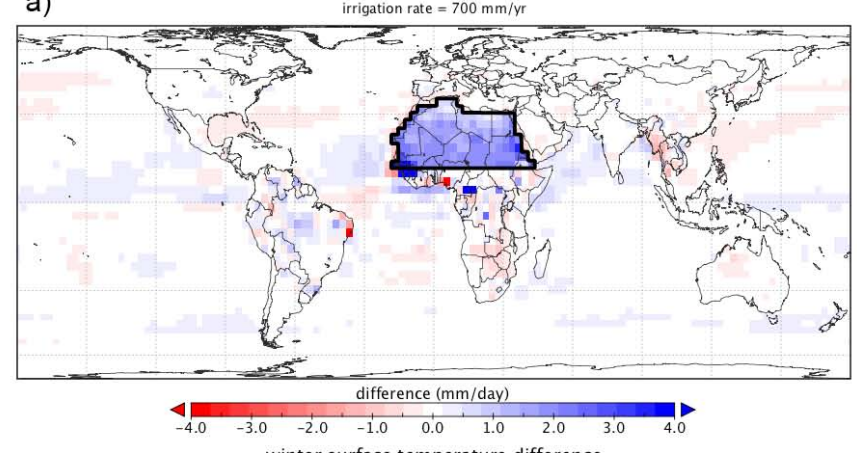

c)

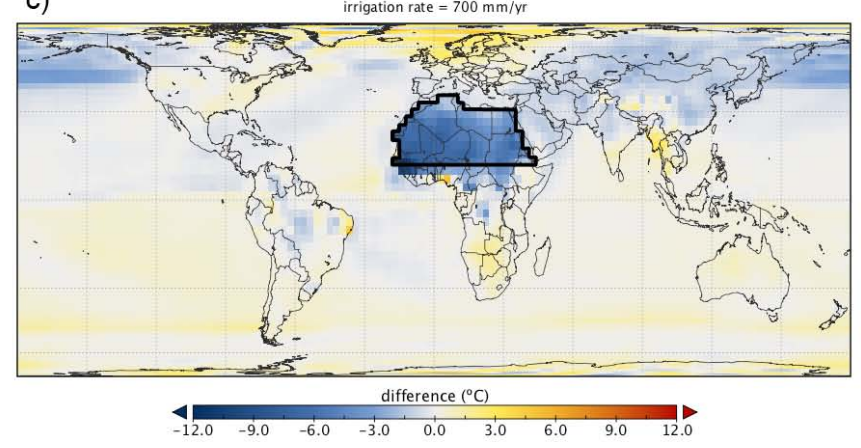

e)

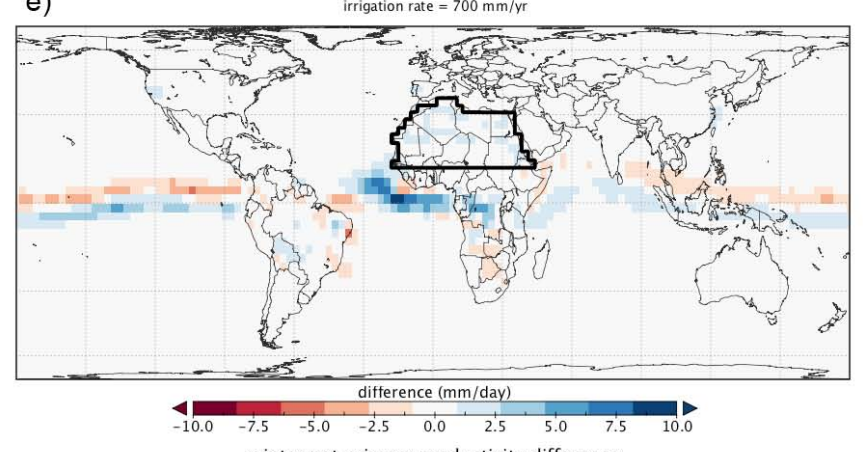

g)

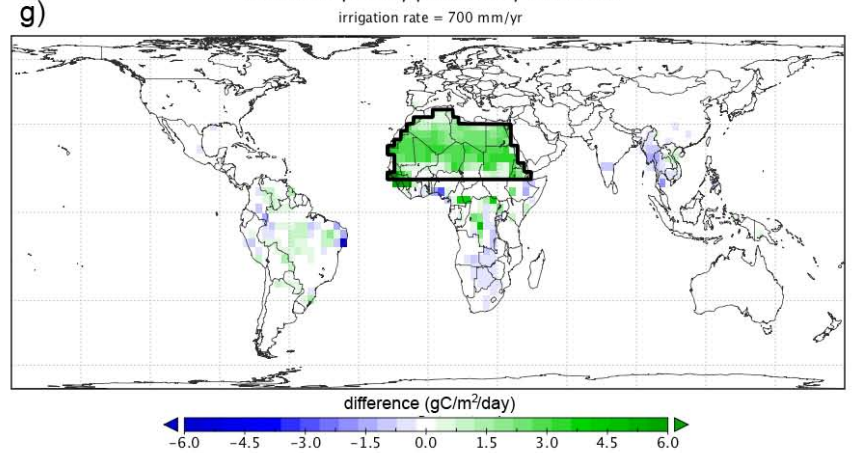

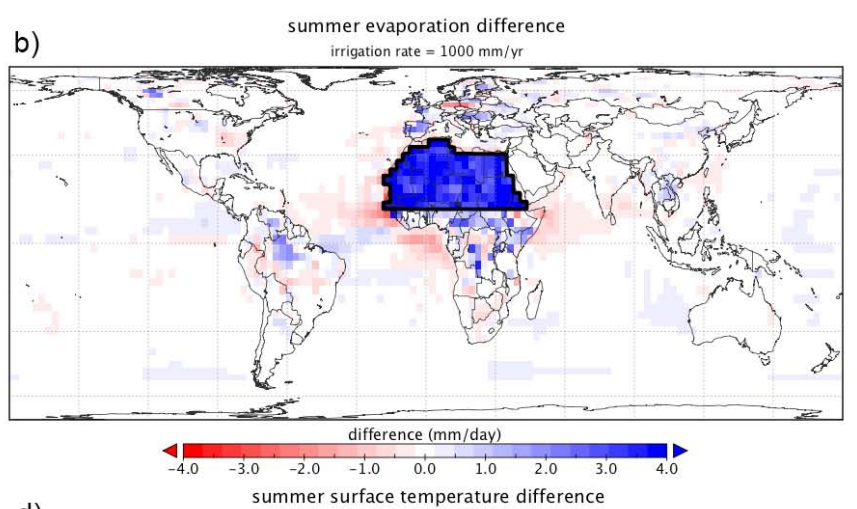

d)
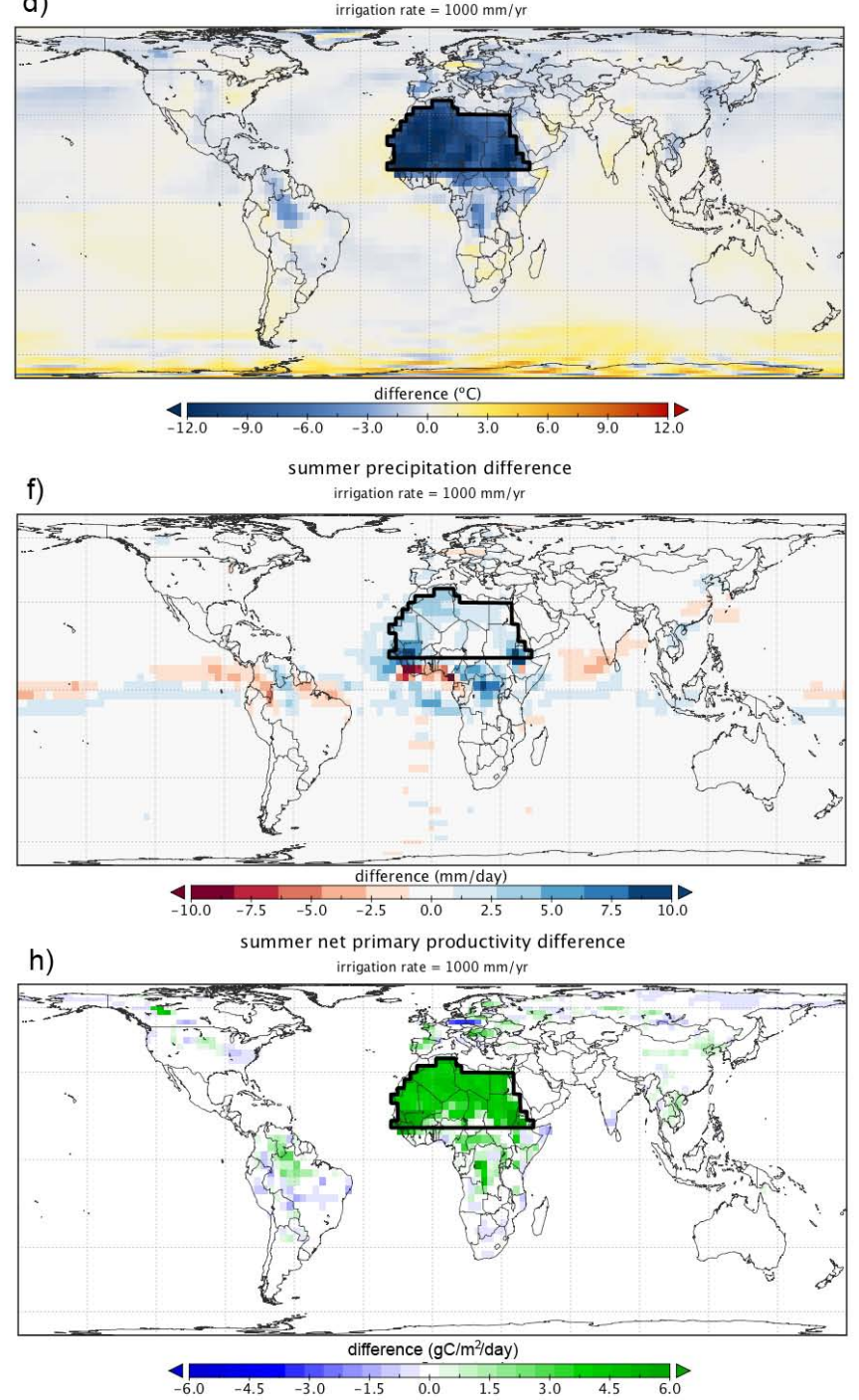

Fig. 4. Differences in evaporation (a, b), surface temperature (c, d), precipitation (e, f), and net primary productivity, or NPP (g, h) during winter (left panels) and summer (right panels); winter compares the $700 \mathrm{~mm} \mathrm{yr}^{-1}$ and control simulations for December-February, while summer compares the $1000 \mathrm{~mm} \mathrm{yr}^{-1}$ and control simulations for June-August, with the black solid line bounding the Sahara/Sahel identifying the irrigated region. Note the significant differences in both variables in regions outside the irrigated region, particularly in southern Africa, southern Europe and northern Latin America. The corresponding southward shift in the inter-tropical convergence zone (ITCZ) is clearly visible in both winter (e) and summer (f). 
radiation input, and simultaneous greater latent cooling of the landmass during summer compared to winter. The eastern and northeastern regions see a small precipitation increase during the summer, shown in Fig. 4f.

The cluster of grid cells within the irrigated region in which NPP and precipitation are consistently higher than others during winter and summer is in the southwestern coastal portion of the irrigated region (roughly $12^{\circ} \mathrm{N}, 10^{\circ} \mathrm{W}$ ), owing to its coastal, equatorial positioning. This implies high year-round solar radiation input.

These observations have important implications for the EROI analysis of irrigation: maximum sustainability of irrigation requires a maximum precipitation feedback, because if water is evaporated and advected elsewhere, particularly over the ocean, it can arguably be considered "lost" in energy-investment terms. This loss is clearly evident in winter, when most of the change (increase) in precipitation occurs over the equatorial Atlantic (Fig. 4e), resulting in a systematically lower EROI across the majority of the irrigated region. Overall, from the perspective of EROI efficiency of irrigation, preferable desert greening areas in our simulations are likely to be those on the western and northwestern coastal boundaries of our irrigated region in the Sahara/Sahel.

\subsection{Interpreting large-scale impacts}

The impact of evapotranspiration at both regional and global levels is greatest in the Northern Hemisphere summer, which is consistent with previous studies simulating enhanced African soil moisture (Cook et al., 2004; Hagos et al., 2005; Ornstein et al., 2009). These describe a shutdown of the African easterly jet (Hagos et al., 2005; Patricola and Cook, 2008; Ornstein et al., 2009), which in the control circumstances retards the monsoonal westerlies from developing polewards of $15^{\circ} \mathrm{N}$. With desert greening, latent cooling due to evaporation and evapotranspiration gives rise to the subsequent domination of monsoonal feedback on circulation and precipitation regimes over the coastal region. This would counteract the surface trades, leading to an increase in coastal sea surface temperatures during summer, as can be seen in Fig. 4d, which could degrade coastal-boundary Ekman pumping there, in agreement with previous findings by Liu et al. (2004), Braconnot et al. (2007) and Ornstein et al. (2009).

These effects are an amplification of circulation patterns already in place in the control or present-day scenario, whereby southerly and northerly winds in conjunction with supply of moisture to the lower troposphere shifts the focal point of convergence from the African coast to the continental interior (Hagos et al., 2007). This change is reflected as a latitudinal shift in maximal precipitation from the Gulf of Guinea in early May to the north of Africa (Hagos et al., 2007). That this effect is amplified in our simulations is supported by the strong decrease in summertime precipitation in the gulf, implying a northward shift of the entire mechanism, driven by the apparent latent heating and enhanced moisture supply to the lower troposphere.

The monsoonal effect appears to drive in the opposite direction in winter: tropical easterly flow over the irrigated region will tend to increase substantially in winter, resulting in high levels of moisture convergence over the equatorial Atlantic, as was shown by Hagos et al. (2005), and the large increase in winter maritime precipitation seen in Fig. 4c.

\subsection{Summary and implications}

Reiterating that this is a conceptual study focused on applying EROI to large-scale desert greening of the Sahara/Sahel, EROI introduces a new way to quantify such large-scale human interventions on the Earth system. Herein, the numerous complexities associated with implementing such an immense project have been largely overlooked, preferentially framing this as more of a conceptual application of EROI than any proposition that such a large-scale desert greening type scenario should be put into action. Given this context, there are four overarching results from these sensitivity simulations.

First, the energy return in many parts of the irrigated region is greater than $1: 1$. This means, perhaps surprisingly, that in conventional investment terms we have an excess of direct $\left(\mathrm{EROI}_{\mathrm{A}}\right)$ energetic profits averaged over the entire irrigated region of $30 \%$ in winter and $80 \%$ in summer (Fig. 1a). EROI B $_{\mathrm{B}}$, which includes the precipitation feedback, increases this to $60 \%$ in winter and to $160 \%$ in summer, an effective doubling. These figures appear to imply that desert greening could be "worth it" in the thermodynamic sense, notwithstanding the energetic cost of outlay and maintenance. Nonetheless, such energetic returns are relatively low compared to those, e.g., of other renewable energy technologies (Hall et al., 1986; Murphy and Hall, 2010).

Second, there are regions of the western coastal Sahara/Sahel in which the EROI given by irrigating the whole irrigated region can be expected to approximate the EROI of those regions or grid cells if they were irrigated in isolation or small clusters. Although only an indirect and imprecise deduction, the assumption seems reasonable given that we can infer this precipitation to be a direct thermal effect of irrigation quantity, not irrigation scale (at least at this grid resolution), and that the precipitation is not sourced from irrigation water pumped into other grid cells (see Sects. 4.1 and 4.2). As noted previously, we cannot confirm these inferences, which will require considerable further investigation and modeling runs to determine.

Third, irrigation of the entire region produces large-scale regional and global teleconnection effects (as also found by Hagos et al., 2005, and discussed in Ornstein et al., 2009) proportional to the quantity of irrigation water supplied. This raises concerns of irrigation scale, and would need to be evaluated in more detail in the future. 
Fourth, our simulation output is consistent with the findings of other studies that used different climate models and simulation scenarios to estimate the outcome of desert greening. Atmospheric circulation changes, teleconnections on both a regional and global scale, shifts of the ITCZ, orographic effects, and even the optimal mean irrigation rate, are supported by previously published research. This gives both the direct output and the inferences made herein a high level of corroboration.

Our EROI ${ }_{\mathrm{B}}$ term extends the definition given by Murphy and Hall (2010) to include the precipitation feedback as an energetic gain. Indeed, since the exergy content of the initial and maintenance capital investment in this desert greening scenario have been negated here for simplicity, our EROI ${ }_{B}$ is equivalent to exergy return on exergy invested as given in Bakshi et al. (2011).

\subsection{Limitations and future research}

Considerable research is still needed to grasp the full exergetic content of the carbon farming life cycle, by expanding the implicit boundaries of the "closed system" used here. Here, we focused our attention on the irrigated region of the Sahara/Sahel, yet these global model simulations also show changes to NPP and precipitation in distant regions of India, the Amazon, southern Europe, eastern Asia, and North America. We expect that these changes are in part related to the extreme spatial scale and irrigation intensity of our experimental setup, with these changes being less pronounced if irrigation was only applied to a few dispersed locations. Developing desert greening in select locations, such as the southwest coastal region of the Sahara, seem the most promising from the EROI perspective.

Taking these thoughts a bit further, even low-elevation coastal regions will require a large energy source for desalination and pumping. EROI ratios greater than $1: 1$ would enable the harvested plant material to be used as the desalination energy source (e.g., Becker et al., 2013) and still be selfsustaining, with the remainder equivalent to an operational profit. This energetic profit may increase further if photovoltaics or concentrated solar power is used as the energy source, especially if these solar technologies were deployed in adjacent locations with a low EROI.

Even with a sufficient energy source for desalination and pumping, desalinated water still contains salts (Elimelech and Phillip, 2011), which would challenge a long-term desert greening type strategy for food production or carbon farming. Mitigating strategies such as the full or cyclical use of halophytes as a form of bioremediation (Flowers et al., 2010) and the growth response of arid plants to subsurface drip irrigation (as dust may then accumulate on the leaves) requires further study. This type of plant-type selection is also specific to the intention, as the plant types that maximize food production or maximize water and energy efficiency in the biome might be quite different.
Studies such as Baudena et al. (2008) have shown that "tipping point" regimes between hot/dry and cool/wet states differ substantially between natural and cultivated monoculture vegetation, in which cultivated areas necessitate a higher vegetation fraction and initial soil moisture levels in order to sustain the $\mathrm{cool} / \mathrm{wet}$ state. Other related microscale soilvegetation-atmosphere feedbacks that induce greater water retention, precipitation, and moisture-recycling over the irrigated area, as discussed with respect to vegetation cover type by Scheffer et al. (2005) and with respect to arid regions in Janssen et al. (2008), require specific investigation, as neither mechanism is included in our model. As desert greening can be viewed as a type of agricultural cultivation, utilizing such non-conventional cultivation regimes like agro-ecology and conservation agriculture could be advantageous, for example by focussing on perennials (i.e., Jackson, 2011). These types of plant strategies and associated ecosystem responses may have non-trivial implications for irrigation, EROI, and the precipitation feedback and therefore deserve further research.

One interesting area of discussion related to desert greening concerns its possibility of existing as a self-sustaining vegetated "green" system, representing one of two alternative stable states that are thought to exist in the Sahara/Sahel (Brovkin et al., 1998; Claussen et al., 1999). This could summarized as follows: given the necessary areal extent and rate of additional water availability, the precipitation (Charney) feedback - which is induced by the change in surface albedo, irrigation, and subsequent evapotranspiration and latent heat release - sustains a vegetated state of the region (Charney, 1975; Charney et al., 1975, 1977; Ornstein et al., 2009; Becker et al., 2013). Note that this vegetated region and the associated dynamics now requires continual human intervention to maintain this altered state, as these changes are made possible by temporarily irrigating the region with desalinated water. Should this alternate steady state result, it would greatly increase the EROI over those simulated in this analysis. Conversely, if such a steady state exists, it is likely that this "tipping point" scale and water input rate may not coincide with the EROI-optimal locations and irrigation input levels identified herein. As also concluded by Becker et al. (2013), we would expect that at least some humanprovided water input would always be required to sustain desert greening in this region, especially in those regions distant from the coast, although the scale of irrigation most likely plays a central role in the extent to which this expectation applies.

Finally, the formulation of EROI used here could be further extended to include other energetic impacts of desert greening. Using the approach of Lenton and Vaughan (2009), the changes in radiative forcing induced by desert greening could be classed into shortwave (albedo) and longwave (atmospheric $\mathrm{CO}_{2}$ ) radiative forcing reductions. These reductions could then be multiplied by some representative energetic value for radiative forcing. In this way, an "EROI ${ }_{c}$ " 
value would consider not only the energetic inputs and outputs required for a given activity such as desert greening, but would also include the per energy-unit net radiative forcing reduction.

To review, $\mathrm{EROI}_{\mathrm{a}}$ considers the stored energy content of the plant biomass and the energy input required for desalination and pumping, while $\mathrm{EROI}_{\mathrm{b}}$ extends this by additionally including the precipitation feedback. EROI ${ }_{c}$ would more fully encompass the system dynamics, as there are accompanying changes in albedo due to changes in net global cloud cover and vegetation, thereby causing a change in global radiative forcing induced by irrigating the Sahara/Sahel.

Viewed specifically from the EROI perspective, as the net carbon sequestration rate and energy input for desalination and pumping is known, it would be possible to estimate this $\mathrm{EROI}_{\mathrm{c}}$ value. However, because radiative forcing is given in units of watt per square meter $\left(\mathrm{W} \mathrm{m}^{-2}\right)$, and the reductions entailed by greening would need to be converted to "energy" (in joules), some multiplier representative of the mean energy required to otherwise reduce one unit of radiative forcing could allow this factor to meaningfully enter EROI calculation. This reduction could then be added to the energy output term (the numerator in Eq. 3).

This type of analysis shows the potential for opening up the scope of EROI to investigate the overall effects of human activities or technological processes - via their relative energy inputs and outputs - on the environment at local, regional and planetary scales. For example, the cultivation of certain types of staple crops around the world will have different energy input and (calorific) output ratios, while differently affecting land-atmosphere interactions and gaseous emissions, with attendant impacts on the global energy balance (imagine, for example, rice versus wheat). Both existing and proposed changes to the makeup of global crops could be subjected to an EROI analysis such as the one undertaken here. Likewise, the composition of, and distribution between, the suite of renewable energy technologies at regional or global scales could also be assessed for relative sustainability using EROI analysis.

\section{Conclusions}

This study has shown how applying the "energy return on investment" (EROI) metric to desert greening in the Sahara/Sahel can add a new perspective to such a large-scale human alteration of the Earth system. We find that by quantifying the energy inputs of desalination and pumping, along with the energy output of biomass production, desert greening of this region may be energetically sustainable. This sustainability, as defined by a EROI ratio greater than $1: 1$, has both a spatial and seasonal component. Overall, in response to irrigating the entire Sahara/Sahel region at the same rate, the western Sahara near the coast had the highest EROI of $\approx 6: 1$ after including the additional precipitation feedback.
Recognizing that our experimental setup of irrigating such a large region may be practically problematic due to a variety of logistical and environmental concerns (e.g., changes in global climatology), the outcome that with some irrigation rates, the energy output is greater than the energy input (i.e., EROI $>1: 1$ ) nonetheless implies that desert greening could warrant further investigation. However, we stress that this positive EROI ratio may also be contingent on a variety of energy input factors (e.g., fertilizer, initial construction, and ongoing maintenance), which we do not consider here. Thus, while more research is certainly required before any implementation of desert greening should take place, the benefits in quantifying EROI in a context where human action directly instigates large-scale changes in Earth system dynamics have been demonstrated here.

Acknowledgement. This study was entirely funded by the Max Planck Society through the Max Planck Research Group of A. Kleidon. The authors declare that they have no competing interests.

Edited by: S. B. Roy

\section{References}

Bakshi, B. R., Baral, A., and Hau, J. L.: Accounting for Resource Use by Thermodynamics, in: Thermodynamics And The Destruction Of Resources, edited by: Bakshi, B., Gutowski, T. G., and Sekulic, D. P., 1st Edn., Cambridge University Press, New York, NY, USA, 87-109, 2011.

Baudena, M., D'Andrea, F., and Provenzale, A.: A model for soilvegetation-atmosphere interactions in water-limited ecosystems, Water Resour. Res., 44, W12429, doi:10.1029/2008WR007172, 2008.

Baum, A. W., Patzek, T., Bender, M., Renich, S., and Jackson, W.: The visible, sustainable farm: A comprehensive energy analysis of a midwestern farm, Crit. Rev. Plant Sci., 28, 218-239, 2009.

Becker, K., Wulfmeyer, V., Berger, T., Gebel, J., and Münch, W.: Carbon farming in hot, dry coastal areas: an option for climate change mitigation, Earth Syst. Dynam., 4, 237-251, doi:10.5194/esd-4-237-2013, 2013.

Braconnot, P., Otto-Bliesner, B., Harrison, S., Joussaume, S., Peterchmitt, J.-Y., Abe-Ouchi, A., Crucifix, M., Driesschaert, E., Fichefet, Th., Hewitt, C. D., Kageyama, M., Kitoh, A., Laîné, A., Loutre, M.-F., Marti, O., Merkel, U., Ramstein, G., Valdes, P., Weber, S. L., Yu, Y., and Zhao, Y.: Results of PMIP2 coupled simulations of the Mid-Holocene and Last Glacial Maximum Part 1: experiments and large-scale features, Clim. Past, 3, 261277, doi:10.5194/cp-3-261-2007, 2007.

Brovkin, V., Claussen, M., Petoukhov, V., and Ganopolski, A.: On the stability of the atmosphere vegetation system in the Sahara/Sahel region, J. Geophys. Res.-Atmos., 103, 31613-31624, 1998.

Charney, J. G.: Dynamics of deserts and drought in the Sahel, Q. J. Roy. Meteorol. Soc., 101, 193-202, 1975. 
Charney, J. G., Stone, P. H., and Quirk, W. J.: Drought in the Sahara: a biogeophysical feedback mechanism, Science, 187, 434-435, 1975.

Charney, J. G., Quirk, W., Chow, S., and Kornfield, J.: A comparative study of the effects of albedo change on drought in semi-arid regions, J. Atmos. Sci., 34, 1366-1385, 1977.

Claussen, M., Kubatzki, C., Brovkin, V., Ganopolski, A., Hoelzmann, P., and Pachur, H. J.: Simulation of an abrupt change in Saharan vegetation in the Mid-Holocene, Geophys. Res. Lett., 26, 2037-2040, 1999.

Cook, K. H., Hsieh, J. S., and Hagos, S. M.: The Africa-South America Intercontinental Teleconnection, J. Climate, 14, 28512865, 2004.

Elimelech, M. and Phillip, W. A.: The future of seawater desalination: Energy, technology, and the environment, Science, 333, 712-717, 2011.

Flowers, T. J., Galal, H. K., and Bromham, L.: Evolution of halophytes: multiple origins of salt tolerance in land plants, Funct. Plant Biol., 37, 604-612, 2010.

Fussel, H.-M.: An updated assessment of the risks from climate change based on research published since the IPCC Fourth Assessment Report, Climatic Change, 97, 469-482, 2009.

Gebel, J. and Yüce, S.: An Engineer's Guide to Desalination, VGB PowerTech Service GmbH, Essen, Germany, 2008.

Gutowski, T. G., Sekulic, D. P., and Bakshi, B. R.: Preliminary thoughts on the application of thermodynamics to the development of sustainability criteria, Sustainable Systems and Technology, IEEE International Symposium on ISSST'09, Phoenix, AZ, $1-6,2009$.

Hagos, S. M., Samson, M., and Cook, K. H.: Influence of surface processes over Africa on the Atlantic marine ITCZ and South American precipitation, J. Climate, 18, 4993-5010, 2005.

Hagos, S. M., Samson, M., and Cook, K. H.: Dynamics of the West African monsoon jump, J. Climate, 20, 5264-5284, 2007.

Hall, C. A. S., Cleveland, C. J., and Kaufmann, R.: Energy and Resource Quality: The Ecology of the Economic Process, Wiley, New York, 1986.

Jackson, W.: Consulting the Genius of the Place: An Ecological Approach to a New Agriculture, Counterpoint Press, Berkeley, CA, USA, 2011.

Janssen, R. H. H., Meinders, M., Marcel, B. J., Van Egbert, N. E. S., and Scheffer, M.: Microscale vegetation-soil feedback boosts hysteresis in a regional vegetation climate system, Global Change Biol., 14, 1104-1112, 2008.

Kleidon, A.: The climate sensitivity to human appropriation of vegetation productivity and its thermodynamic characterization, Global Planet. Change, 54, 109-127, 2006.
Kleidon, A., Fraedrich, K., and Heimann, M.: A green planet versus a desert world: Estimating the maximum effect of vegetation on the land surface climate, Climatic Change, 44, 471-493, 2000.

Kubiszewski, I., Cleveland, C., and Endres, P.: Meta-analysis of net energy return for wind power systems, Renewable Energy, 35, 218-225, 2010.

Lenton, T. M. and Vaughan, N. E.: The radiative forcing potential of different climate geoengineering options, Atmos. Chem. Phys., 9, 5539-5561, doi:10.5194/acp-9-5539-2009, 2009.

Liu, Z., Harrison, S. P., Kutzbach, J., and Otto-Bliesner, B.: Global monsoons in the mid-Holocene and oceanic feedback, Clim. Dynam., 22, 157-182, doi:10.1007/s00382-003-0372-y, 2004.

Lunkeit, F., Blessing, S., Fraedrich, K., Jansen, H., Kirk, E., Luksch, U., and Sielmann, F.: Planet simulator user's guide version 15.0, Meteorological Institute of the University of Hamburg, Hamburg, Germany, 2007.

Miller, L. M., Gans, F., and Kleidon, A.: Estimating maximum global land surface wind power extractability and associated climatic consequences, Earth Syst. Dynam., 2, 1-12, doi:10.5194/esd-2-1-2011, 2011.

Murphy, D. J. and Hall, C. A. S.: Year in review EROI or energy return on (energy) invested, Ann. New York Acad. Sci., 1185 102-118, 2010.

Odum, H. T.: Environmental Accounting: EMERGY and Environmental Decision Making, Wiley, New York, NY, USA, 1996.

Ornstein, L., Aleinov, I., and Rind, D.: Irrigated afforestation of the Sahara and Australian Outback to end global warming, Climatic Change, 97, 409-437, 2009.

Patricola, C. M. and Cook, K. H.: Atmosphere/vegetation feedbacks: a mechanism for abrupt climate change over northern Africa, J. Geophys. Res.-Atmos., 113, D18102, doi:10.1029/2007JD009608, 2008.

Patzek, T. W.: Thermodynamics of agricultural sustainability: The case of US maize agriculture, Crit. Rev. Plant Sci., 27, 272-293, 2008.

Peixoto, J. P. and Oort, A. H.: Physics of climate, American Institute of Physics, New York, NY, 1992.

Scheffer, M., Holmgren, M., Brovkin, V., and Claussen, M.: Synergy between small-and large-scale feedbacks of vegetation on the water cycle, Global Change Biol., 11, 1003-1012, 2005.

Valero, A. and Valero, A.: A prediction of the exergy loss of the world's mineral reserves in the 21st century, Energy, 36, 18481854, 2011.

Zeng, X. D., Zeng, X. B., and Barlage, M.: Growing temperate shrubs over arid and semiarid regions in the Community Land Model-Dynamic Global Vegetation Model, Global Biogeochem. Cy., 22, GB3003, doi:10.1029/2007GB003014, 2008. 